\title{
EN TRÁNSITO: UN RECORRIDO POR LA ROAD MOVIE NORTEAMERICANA
}

\author{
ON THE MOVE: A TOUR THROUGH AMERICAN ROAD MOVIE
}

\author{
Santiago GARCÍA OCHOA \\ IES Manuel Chamoso Lamas \\ santiagogarciaochoa@gmail.com
}

\begin{abstract}
Resumen: La road movie no puede considerarse un género canónico. Su origen a finales de los 60 , en plena crisis del cine clásico, explica su especial condición de intergénero. A pesar de ello, la road movie posee una poética propia que viene definida por la estructura narrativa en torno al desplazamiento por carretera, el empleo de unos recursos técnicos concretos (como el camera car), el protagonismo tradicionalmente masculino o el sentido metafórico del viaje. Desde su nacimiento, coincidiendo con New Hollywood (1967-1975), a la actualidad, el género ha experimentado una serie de cambios significativos, como la incorporación de colectivos tradicionalmente no representados (mujeres, enfermos, gays, ancianos, la familia).
\end{abstract}

Palabras clave: Viaje. Cine norteamericano. Géneros cinematográficos. Road movie.

Abstract: Road movie is not a canonical genre. At the end of the sixties, in the middle of the crisis of classic cinema, its origin explains its special inter-genre status. However, the road movie has its particular poetics that is defined by the technical resources (such as the camera car), the tradi- 
tional main male protagonism and the travel's metaphorical meaning. This genre has undergone some significant changes from its beginning, when the New Hollywood took place (1967-1975), to nowadays, such as the incorporation into the trip of traditionally unrepresented groups (women, the sick, gays, elderly, the family).

Key Words: Trip. American Cinema. Film Genres. Road Movie.

\section{BREVE ESTADO DE LA CUESTIÓN}

La espectacular proliferación de la road movie en la década de los 90, tanto en EE.UU. como en las cinematografías de todo el mundo, despertó el interés académico por estudiar un género tan multiforme como controvertido. Timothy Corrigan (1991) fue el primero en enfrentarse a esta problemática, en un capítulo de su célebre A Cinema Without Walls: Movies and Culture after Vietnam, dedicado al cine de los 70 y los 80 . David Laderman (2002) es el que le ha dado un tratamiento más completo y coherente dentro del ámbito norteamericano ${ }^{1}$. En las últimas décadas han aparecido incluso monografías consagradas al estudio de la road movie en diversas cinematografías nacionales, como la española (Pérez, 2011), la francesa (Archer, 2013) o la brasileña (Brandellero, 2013).

Dos son los principales puntos negros que se observan en la bibliografía especializada hasta la fecha: las discrepancias sobre el origen del género y las dificultades para definir de forma exclusiva su carácter autónomo frente a otros géneros anteriores.

Existe una serie de autores que prescinden de una acotación histórica y/o geográfica para la road movie. Steven Cohan e Ina Rae Hark, por ejemplo, la consideran un género más (como el western o el musical) del cine norteamericano de los años 30 (citan It Happened One Night [Sucedió una noche, Frank Capra, 1934] y The Grapes of Wrath [Las uvas de la ira, John Ford, 1940]): "The impact of Easy Rider is undeniable and important to any understanding of the genre, but it has also obscured the road movie's own history" (Cohan y Hark, 1997: 4). Por su parte, Devin

1. Fuera de EE UU destaca sobremanera el estudio del italiano Giampiero Frasca (2001). 
Orgeron afirma que se trata de un fenómeno sin fronteras unido al desarrollo de la movilidad: "More than a study of any single generic category, its attending history, or its iconography, Road Movies makes a case for the cinema's trans-national, trans-historical and trans-generic attraction to the subject of transportation" (Orgeron, 2008: 2).

Aquí defendemos, como gran parte de la bibliografía publicada a partir de Corrigan (1991), que la road movie surge en EE.UU. a finales de los 60 propiciada por la coyuntura favorable de New Hollywood (1967-1975) ${ }^{2}$, a partir de una serie de elementos preexistentes típicamente norteamericanos, como el espíritu renovador de la extensión de la frontera ${ }^{3}$ y la literatura (Mark Twain o Jack London) y el cine (el western) desarrollados en torno a él; la highway culture fraguada tras la II Guerra Mundial ${ }^{4}$ y la contracultura, a partir de la novela On the Road de Jack Kerouac, publicada en $1957^{5}$, cuyo éxito inmediato convirtió a la generación beat en un fenómeno de masas $^{6}$. Bruce Cook considera que existe toda una tradición literaria del vagabundo que parte de Adventures of Huckleberry Finn (Mark Twain, 1884), llega a Kerouac y se prolonga hasta Easy Rider (Easy Rider. En

2. Algunos historiadores denominan de forma genérica postclasicismo o New Hollywood a lo que viene después del periodo clásico, estableciendo una dialéctica general entre lo viejo y lo nuevo. Otros prefieren restringirla a fases más específicas dentro de este marco tan amplio, generalmente al periodo 1967-1975, por considerarlo la fase de transición que conduce al Hollywood actual (postclásico pero también posmoderno). Somos partidarios de esta segunda acepción del término.

3. La importancia que han tenido los movimientos migratorios en la formación y el devenir histórico de EE.UU. ha sido ampliamente reconocida por la historiografía, especialmente a partir de la teoría de la fronte$r a$ acuñada a finales del siglo XIX por Frederick J. Turner: "American social development has been continually beginning over again on the frontier. This perennial rebirth, this fluidity of American life, this expansion westward with its new opportunities, its continuous touch with the simplicity of primitive society, furnish the forces dominating American character. The true point of view in the history of this nation is not the Atlantic coast, it is the Great West" (Turner, 1961: 38).

4. En diciembre de 1944, el presidente Roosevelt firmaba la Federal Aid Highway Act donde se establecía la construcción de cuatro tipos de carreteras: para transporte, rurales, urbanas e interestatales; pero el verdadero impulso llegaría en 1956 con la firma por el presidente Eisenhower de una nueva Federal Aid Highway Act para la construcción de un sistema de autopistas interestatal. Una auténtica euforia se despertó ante las posibilidades que ofrecerían las nuevas infraestructuras, por fin los ciudadanos podrían acercarse a los paisajes naturales que constituían "The Face of America" (título de la colección de fotografías publicada por The Saturday Evening Post en 1957, en la que se mostraban la riqueza y variedad natural de las distintas regiones del país). La autopista pasó a ser considerada, en sí misma, una nueva maravilla.

5. Una primera versión de la novela fue mecanografiada por Kerouac en 1951 a espacio sencillo y sin corte de párrafo sobre tiras de papel de calco pegadas entre sí formando un rollo de 36 metros: "A long roll of paper like the remembered road that he could write fast on and not stop. So that the paper joined together became an endless page" (Cunnell, 2007: 24).

6. La generación beat comprendió a un grupo de autores desencantados (Jack Kerouac, William Burroughs y Allen Ginsberg son los más conocidos) de la década de los 50 que cuestionaron los valores norteamericanos clásicos y escribieron sobre el consumo de drogas y la libertad espiritual poniendo las bases de lo que luego será el movimiento hippy. 
busca de mi destino, Dennis Hopper, 1969) (Cook, 2011: 41-43)7.

\section{2. ¿UN GÉNERO CINEMATOGRÁFICO?}

El cine, como cualquier otro arte o industria, se clasifica desde múltiples facetas y criterios: formato, nacionalidades, productoras, géneros, etc. El término género se aplica al cine comercial, hecho de acuerdo con unas fórmulas más o menos estandarizadas reconocibles por cualquier espectador, en contraposición al cine de autor, caracterizado por la experimentación formal y narrativa. Los géneros cinematográficos son, sin duda, uno de los criterios más populares y recurrentes para clasificar las películas, aunque también uno de los más discutidos y menos estables.

Desde un punto de vista estrictamente industrial, la clasificación por géneros respondió a las exigencias del studio system norteamericano, como respuesta a las peculiaridades y demandas del mercado, en paralelo al triunfo del modelo clásico. Los géneros proporcionan a los emisores (productores, directores, guionistas...) unas pautas o patrones de producción discursiva y a los destinatarios (espectadores, críticos, historiadores) cánones para hacer los textos más legibles. Cada género posee una poética característica que se manifiesta tanto a través de sus elementos aislados (personajes, ambientes...) como por la forma en que estos se relacionan entre sí (sintaxis, estructuras características). Rick Altman (1984) fue el primero en reivindicar esta naturaleza dual (semántica y sintáctica) de los géneros, al desarrollar un planteamiento teórico que recogía los tradicionales aspectos temáticos y de puesta en escena (elementos paradigmáticos o verticales) y los combinaba con el enfoque sintáctico, centrado en las estructuras en que se disponen esos bloques (la sintagmática o plano horizontal).

Precisamente, en uno de los últimos libros publicados sobre la road movie, Neil Archer (2016: 2-3) parte de esta aportación de Altman para establecer que la presencia de una determinada iconografía (coches, persecuciones), en títulos como Drive (Nicholas Winding Refn, 2011) o Collateral (Michael Mann, 2004), no determina por sí sola la configuración de una road movie: "But it is hard to call Drive or Collateral road movies,

7. No está de más recordar que la obra de Cook (publicada originalmente en 1971) fue la primera crónica sobre los orígenes y el desarrollo de la generación beat que vio la luz. 
not so much because they remain within Los Angeles, but because other semantic and syntactic elements adhere more closely to the expectations of the crime film, the detective film or the thriller" (Archer, 2016: 3).

Los grandes géneros (la comedia, el drama, el cine de terror o el policiaco) poseen una larga historia de cambios íntimamente ligados al contexto político y social. Pero existen muchas más categorías o géneros menores que convierten la lista en casi interminable, sin existir un acuerdo unánime en cuanto a su clasificación.

Sánchez Noriega clasifica los géneros en canónicos, híbridos e intergéneros o ciclos intergenéricos. Los géneros canónicos son los del cine clásico: drama o melodrama, western, comedia, musical, terror, fantástico o ciencia-ficción, aventuras o acción y criminal (cine negro, policiaco, thriller). Dentro de cada género canónico caben unas especializaciones o géneros menores, y subgéneros o ciclos (comedia romántica, aventuras exóticas); aunque la diferencia entre ambas categorías resulta difusa, sobre todo porque el término subgénero suele emplearse con sentido peyorativo para referirse a ciclos de poca calidad dentro de un género canónico. Los géneros híbridos acogen a aquellas películas que participan de más de uno de los géneros canónicos: comedia dramática, comedia musical, péplum (drama histórico de la antigüedad + aventuras), catástrofes (drama + aventuras). Los intetergéneros comprenden catálogos de películas que pueden pertenecer indistintamente a uno o más de los géneros canónicos pero que se identifican por un tema específico (cine de mujeres) o por una estructura concreta (películas de carretera) (Sánchez, 2002: 99-101).

El nacimiento de la road movie coincide con la crisis del cine clásico, dentro del periodo conocido como New Hollywood (1967-75), momento de extrema convulsión política y social en EE.UU. De entre los acontecimientos que suceden podrían destacarse los siguientes: asesinato de importantes líderes políticos, como Martin Luther King y el senador Robert Kennedy (ambos en 1968), recrudecimiento de la guerra de Vietnam y de los movimientos de protesta, crisis del petróleo a partir de 1973, dimisión de Nixon a causa de su implicación en el escándalo Watergate (1974). Todo ello se tradujo en la total desconfianza de los ciudadanos hacia los políticos federales, estatales y municipales.

New Hollywood supone la materialización de grandes cambios en la organización industrial y económica de Hollywood, en gran medida por la competencia del medio televisivo, pero también la entrada de la moderni- 
dad cinematográfica, debida a la influencia de los nuevos cines europeos. Los críticos norteamericanos de los 60 (con Andrew Sarris a la cabeza) absorbieron la política de los autores (diseñada por la revista francesa $\mathrm{Ca}$ hiers du Cinéma) y las universidades crearon los primeros departamentos de cine. Por fin, el director dejaba de ser considerado un mero engranaje dentro del studio system para pasar a convertirse en el verdadero protagonista del proceso de producción de una película, en el autor de la obra. En otras palabras: por primera vez en Hollywood la etiqueta de cine de autor se imponía a la de cine de género.

El concepto de género cinematográfico se ve también inevitablemente alterado desde finales de los 60 por la diversificación del público, imposible de reducir a un modelo unitario. La configuración de grupos sociales diferenciados por su raza, sexo o edad que luchan por ampliar sus derechos en el marco de la sociedad democrática resulta capital para comprender este fenómeno. El modelo homogéneo del Viejo Hollywood, basado en la asistencia de las familias al cine resultaba obsoleto para la sociedad del momento. De todos los grupos sociales el que se diferencia por su edad, los jóvenes, es el que cobra ahora un mayor protagonismo. El incremento de los recursos económicos tras la II Guerra Mundial y la larga etapa de formación condujo a que los adolescentes (y los jóvenes adultos para el caso de los universitarios) fuesen creando unas señas de identidad propias basadas en la rebeldía frente a los valores defendidos por los adultos y por el propio sistema vigente, al que identificaban con sus padres (contracultura). El proceso se inicia con el triunfo del rock and roll y la generación beat durante la década de los 50 y se generaliza en los 60 con el desarrollo del movimiento hippy.

Una investigación encargada por la Motion Picture Association of America (MPAA, la organización que defendía los intereses comerciales de los estudios de Hollywood) en 1968 reveló que el 48 \% del público que asistió a las salas ese año pertenecía al grupo de los 16-24 años (Cook, 2002: 67). Eran los niños del baby boom posbélico (1946-1964), que no sólo habían tenido una educación más larga y completa, sino que para ellos el lenguaje audiovisual (y por extensión el cine de Hollywood) resultaba algo de lo más cotidiano: porque crecieron pegados a la televisión en sus casas unifamiliares de las ciudades dormitorio. Su mirada se encontraba ya hipertrofiada por la constante repetición en la pantalla (tanto cinematográfica como televisiva) de las mismas convenciones genéricas. 
La road movie debe catalogarse pues como un fenómeno genérico impuro, de naturaleza intertextual, no en vano las películas de carretera siempre se pueden enmarcar claramente dentro de, al menos, uno de los géneros clásicos (drama, comedia, policiaco, etc.).

\section{LA POÉTICA DE LA ROAD MOVIE}

Dentro del cine norteamericano, la estructura narrativa en torno al desplazamiento tiene un primer desarrollo en el western, género histórico consagrado a poner en imágenes el proceso de colonización del país. Un ejemplo muy citado es Stagecoach (La diligencia, John Ford, 1939). A finales de los 60 las similitudes entre el western y la road movie se acentúan, sirvan de ejemplo Butch Cassidy and the Sundance Kid (Dos hombres y un destino, George Roy Hill, 1969) y The Wild Bunch (Grupo salvaje, Sam Peckinpah, 1969). En la road movie la narración queda inevitablemente unida al contexto espacial de la carretera, es decir, el relato progresa en paralelo al desplazamiento de los protagonistas en sus vehículos.

Frasca distingue cuatro etapas en la estructura de la road movie (tomadas de la novela picaresca):

a) Breve presentación del entorno del protagonista regido por un aparente equilibrio, ya que en realidad resulta opresivo.

b) El protagonista inicia su viaje en busca de nuevas ilusiones y perspectivas.

c) El personaje va conociendo lugares y personas extrañas (ajenos a su entorno de origen). De todo extrae enseñanzas.

d) El protagonista ha adquirido una nueva conciencia, que le permite contemplar el mundo de manera distinta: el balance puede ser positivo (ha obtenido el objetivo inicial y concluye el viaje), negativo (no lo ha obtenido y prosigue el viaje), e incluso nulo (ha descubierto la imposibilidad de conseguirlo) (Frasca, 2001: 55).

Los protagonistas de las road movies viajan en busca de la libertad, representada simbólicamente en la carretera. De ahí que la policía adquiera casi siempre un carácter peyorativo, funcionando como una amenaza, un obstáculo hacia la consecución de esa libertad, especialmente en las car chase movies: "It is important to note that the protagonists escape in a car, but the police have a wide variety of vehicles and tools at their disposal, including the use of helicopters" (Kleparski y Martynuska, 2008: 72). El 
inicio del viaje puede responder a diferentes causas que, según Frasca, engloban tres motivaciones: deliberada (la salida responde a la voluntad de los personajes, para dirigirse a algún lugar o acontecimiento), externa (existe una razón que los obliga a escapar, como la huida de la policía o de la mafia) y existencial (es el rechazo de un entorno opresivo lo que hace partir a los personajes) (Frasca, 2001: 142-145). No obstante, aunque exista una causa definida para el inicio del viaje, ésta suele diluirse pronto. La meta final del viaje también terminará resultando irrelevante, es el viaje en sí mismo lo que cuenta, por eso la road movie puede estilizarse hasta el extremo de convertirse en un puro reflejo de la estructura del género, como en Two Lane Blacktop (Carretera asfaltada en dos direcciones, 1971) (Weinrichter, 1979: 126-127), en la que los personajes evolucionan hacia la anulación o la nada, se identifican con el devenir sin destino. En algunos casos el viaje concluye con la muerte de los protagonistas: Bonnie and Clyde (Bonnie y Clyde, Arthur Penn, 1967), Easy Rider, Vanishing Point (Punto limite: cero, Richard C. Sarafian, 1971) o Thelma and Louise (Thelma y Louise, Ridley Scott, 1991). Atkinson ha resumido a la perfección el espíritu del género: "[...] they [road movies] express the fury and suffering at the extremities of civilised life, and give their restless protagonists the false hope of a one-way ticket to nowhere" (Atkinson, 1994: 16).

El espacio que recorren los personajes de las road movies se carga de sentido metafórico, influye de manera decisiva en su viaje interior, cobrando especial relevancia las diferentes paradas, los lugares, el paisaje y los encuentros. Espacios característicos de la road movie son, además de la propia carretera y el interior los vehículos, todos los que han sido codificados por la generalización del uso del coche (sistema del automóvil): moteles, gasolineras, restaurantes... La ciudad puede aparecer como punto de partida, paso o llegada. Estos espacios representan el entorno mecanizado propio de una sociedad industrial avanzada, en clara oposición a los paisajes salvajes y la sociedad naciente del western; y el viaje funciona como una alegoría de la evolución de los EE UU, casi siempre como un retrato de una sociedad degradada que oprime al protagonista. En palabras de Frasca: “[...] se il viaggio rappresenta la metafora dell'esistenza dell'America, il Road Movie è la rappresentazione disillusa della cattiva coscienza del Paese" (Frasca, 2001: 10). 


\section{DE NEW HOLLYWOOD A LA ACTUALIDAD: EVOLU- CIÓN DE LA ROAD MOVIE}

La road movie nace tan unida a la coyuntura de New Hollywood que ambos fenómenos se confunden, o lo que es lo mismo: algunas de las primeras y más emblemáticas películas de New Hollywood son también las primeras road movies, como Bonnie and Clyde, Easy Rider y Two Lane Blacktop. Tres rasgos definen lo que podríamos denominar estilo New Hollywood:

a) Incorporación de nuevas técnicas y procedimientos tomados fundamentalmente de los nuevos cines europeos y la televisión: uso del zum y del teleobjetivo, congelado de la imagen, división de la pantalla en partes (multipantalla), montaje sincopado, eliminación de fundidos en favor del corte neto, importante desarrollo del proceso de edición del sonido (para potenciar el realismo, subrayar el punto de vista de los personajes o incluso fusionarse con la música) y predominio del rodaje en escenarios naturales con equipos menos pesados, cámara al hombro, camera car, etc. (que favorecen el recurso al plano-secuencia).

b) Crisis de la coherencia narrativa clásica, basada en presentar de forma más o menos clara la evolución de un personaje (héroe) enfrentado a un conflicto que finalmente consigue superar (planteamiento-nudodesenlace). Elsaesser define a estos nuevos personajes como héroes desmotivados indefinidos psicológicamente, invadidos por lo que él llama el pathos del fracaso, lo que provoca la vulneración de la causalidad dentro del relato (Elsaesser, 1975: 13-19). La aparición de un interés por mostrar ambientes y fenómenos característicos de la época desde la óptica del documental también contribuye a neutralizar la narración. La Polla ha observado la influencia de la estética pictórica hiperrealista en el cine de New Hollywood, tanto por el predominio del paisaje urbano y los vehículos motorizados como por un gusto por el detalle (potenciado a través del montaje analítico) que conduce incluso a la introducción en el encuadre de elementos reflectantes (espejos, cristaleras), característicos de la pintura hiperrealista (La Polla, 1978: 163-187). La abundancia de films que recurren al motivo del viaje ejemplifica muy bien la crisis de la coherencia narrativa clásica: en ellos la única línea de acción la marca el desplazamiento de los protagonistas, responsable también de fragmentar la narración, que se convierte en una sucesión de episodios (generados por sus estancias en 
distintos lugares).

No en vano numerosas películas de los nuevos cines europeos se articulan en torno al viaje por carretera, reflexionando de una $u$ otra forma sobre la identidad nacional, rasgo por otro lado característico de toda la modernidad cinematográfica europea desde el neorrealismo italiano:

It can be argued that neorealism was born on the road, and that many neorealistic films were road movies of national, regional, or urban travel that reflected the hunger of post-war Italian film-makers for realism, and which embodied this society's critical and exploratory spirit. Visconti's Ossessione/Obsession (1944); Rossellini's Paisàl Paisan (1946) and Viaggio in Italia/Voyage to Italy [Te querré siempre] (1954); De Sica's Ladri di biciclette/Bicycle thieves [Ladrón de bicicletas] (1948) and Umberto $D$ (1952); and Fellini's La strada/The Road (1954) are examples of such films (Rascaroli, 2005: 251).

Otros títulos europeos igualmente representativos son: Smultronstället (Fresas salvajes, Ingmar Bergman, 1957), À bout de souffle (Al final de la escapada, Jean-Luc Godard 1959), Il sorpasso (La escapada, Dino Risi, 1962), Pierrot le fou (Pierrot el loco, Jean-Luc Godard, 1965) o Stress es tres tres (Carlos Saura, 1968).

Sin olvidar la influencia literaria y cultural de la novela picaresca (a partir del Lazarillo de Tormes) y El Quijote, reformulada por la Bildungsroman (novela de formación) ${ }^{8}$, que narra la historia de un personaje a lo largo del complejo periplo de su formación (moral, sentimental o intelectual; temas constantemente repetidos son el camino, el viaje, la aventura, la prueba) desde la juventud hasta la madurez, cuando el héroe acepta contentarse con determinados valores que le parecen realizables, y que normalmente se corresponden con la ideología dominante (Marchese y Forradellas, 1998: 44), algo contrario al espíritu de las primeras road movies nacidas con New Hollywood. Es por ello que, para nuestros intereses, resultará más apropiado tomar como punto de partida la novela de

8. Con Wilhelm Meisters Lehrjahre (Los años de peregrinaje de Wilhelm Meister, Goethe, 1796) como ejemplo canónico. 
formación moderna, a partir de Hyperion oder der Eremit in Griechenland (1797-9) de Hölderlin:

[...] el carácter fragmentario de las versiones previas, su continua reescritura y el final abierto de la versión definitiva de la novela de Hölderlin (con un Hiperión que termina diciendo algo tan coyuntural y desprovisto de sentido concluyente, consumatorio, como "Así pensaba yo. La próxima vez, más”) evidencian la insuficiencia de esa vida para colmar el anhelo de un individuo que ya no se siente sujeto a una única forma definitiva (Barrios, 2001: 19).

c) Sustitución de los valores tradicionalmente fomentados desde Hollywood por el antiautoritarismo, la ambigüedad ideológica y un tratamiento desinhibido de la violencia y el sexo (gracias a la desaparición del Production Code): Easy Rider recrea de forma plenamente satisfactoria la ideología y las formas de vida (banda sonora compuesta por temas de rock and roll, visita de una comuna hippy, consumo de drogas) de la contracultura ${ }^{9}$. En definitiva, el cine New Hollywood (y también las primeras road movies) presenta una sociedad opresora contra la que los personajes sienten la necesidad de rebelarse (dentro o fuera de la ley).

Bonnie and Cyde y Easy Rider marcan las dos líneas temáticas de desarrollo de la road movie contracultural durante los primeros 70: la huida (key outlaw road movies) y la búsqueda existencial (quest road movies) (Laderman, 2002: 82-83) ${ }^{10}$; y también definen el predominio de la pareja heterosexual o masculina. En cualquier caso, la mayoría de las road movies de los 70 y 80 presentan a hombres como protagonistas, y en las escasas películas en las que aparecen mujeres desempeñando este rol sus intentos emancipadores chocan con los personajes masculinos que se encuentran en su camino, como sucede en The Rain People (Llueve sobre mi corazón, Francis Ford Coppola, 1969), Wanda (Barbara Loden, 1970) y

9. En el lavabo del cine de Nueva York donde se estrenó tuvieron que quitar las puertas de los retretes porque los hippies se metían allí a fumar porros (Biskind, 2004: 93).

10. El autor ilustra el primer tipo con títulos como The Getaway (La huida, Sam Peckinpah, 1972), Badlands (Malas tierras, Terrence Malick, 1973) o The Sugarland Express (Loca evasión, Steven Spielberg, 1974). Del segundo destaca también varios ejemplos, como Five Easy Pieces (Mi vida es mi vida, Bob Rafelson, 1970), Two-Lane Blacktop o Vanishing Point. 
Alice Doesn't Live Here Anymore (Alicia ya no vive aquí, Martin Scorsese, 1974) (Induráin, 2001: 65) ${ }^{11}$. Las mujeres independientes sólo aparecen en el exploitation (cine que enfatiza determinados motivos de carácter mórbido en torno a la violencia y el sexo destinado a circuitos de exhibición secundarios, como los autocines), en títulos como Faster, Pussycat! Kill! Kill! (Russ Meyer, 1965) o The Great Texas Dynamite Chase (Michael Pressman, 1976).

Con la irrupción de la posmodernidad a mediados de los 70 el género inicia una fase revisionista y autorreflexiva: "[...] exaggerates irony and cynicism through stylized spectacles of sex, violence, or simple tonguein-cheek cool. Generic elements become driven by style (think fashion), transformed into images of and for mass popular culture" (Laderman, 2002: 133). Sus protagonistas habitualmente pertenecen al establishment, y se critica la yuppie culture, encarnada en el arrogante y vanidoso importador de automóviles (Tom Cruise) de Rain Man (El hombre de la lluvia, Barry Levinson, 1988), que se va transformando progresivamente mientras viaja por carreteras secundarias con su hermano autista (Dustin Hoffman) de Cincinnati a Los Ángeles. Otra vía muy transitada es la deconstrucción de la road movie en clave paródica, como en la saga de Smokey and the Bandit, que lleva al paroxismo la estructura del gato que persigue al ratón ${ }^{12}$. En las dos primeras entregas, Smokey and the Bandit (Los caraduras, Hal Needham, 1977) y Smokey and the Bandit II (Vuelven los caraduras, Hal Needham, 1980), el sheriff Buford T. Justice (Jackie Gleason), Smokey (término que en el argot de los camioneros sirve para denominar a la policía), persigue al Bandido (Burt Reynolds), el cowboy de la carretera, parodiando la contraposición de arquetipos entre el hombre del Este, que cumple la ley, y el hombre del Oeste, que impone sus propias

11. Siguiendo a Pierre Bourdieu, una demostración más de que la división entre los sexos define el orden simbólico de las cosas y del mundo social. Así, los valores propios de lo masculino: lo recto, lo abierto, lo centrífugo (hacia afuera), pueden asociarse con la carretera, mientras los propios de lo femenino: lo cíclico, lo cerrado, lo centrípeto (hacia dentro), se identifican plenamente con el hogar (Bourdieu, 1991; Bourdieu, 2000). Esta contraposición fue inicialmente explotada por la teoría feminista. Laura Mulvey (1975) considera que en el cine clásico de Hollywood el hombre desempeña el papel de sujeto activo que mira, mientras que la mujer funciona como el objeto pasivo de su deseo. Teresa De Laurentis (1985) analiza la tipología de relatos de Yuri Lotman (1979) y constata la aparición de dos aspectos característicos del relato mítico: el héroe masculino que recorre espacios, y un obstáculo o espacio inmóvil y cerrado que adquiere la forma de casa, cueva o mujer. La presencia de la mujer en la carretera también posee un carácter peyorativo al aparecer tradicionalmente asociado con la prostitución (Mazierska y Rascaroli, 2006: 162).

12. Otros dos buenos ejemplos de ello son The Gauntlet (Ruta suicida, Clint Eastwood, 1977) y Convoy (Sam Peckinpah, 1978). 
reglas, característica del western ${ }^{13}$. En Smokey and the Bandit Part 3 (Los caraduras 3, Dick Lowry, 1983) se da una vuelta de tuerca más: un falso Bandido (encarnado por Cledus [Jerry Reed], el camionero compañero y amigo del auténtico) recibe el encargo de entretener al sheriff Buford, que se salta todas las normas en las persecuciones para intentar ganarle una apuesta a los excéntricos millonarios, padre e hijo, que antaño retaban al Bandido.

En los 90 asistimos al verdadero boom de la road movie, con la continuación de la tendencia autorreflexiva y/o paródica, la recuperación de la vía contracultural y, como fenómeno novedoso, la incorporación de la mujer y de la multiculturalidad. El hombre blanco joven heterosexual (american male), protagonista canónico del género, se ve ahora desplazado por otras alternativas sexuales y raciales on the road: mujeres (Thelma and Louise, Leaving Normal [Dos chicas en la carretera, Edward Zwick, 1992]), gays (The Living End [Vivir hasta el fin, Gregg Araki, 1992], To Wong Foo, Thanks for Everything! Julie Newmar [A Wong Foo, igracias por todo! Julie Newmar, Beeban Kidron, 1995]), indios americanos (Powwow Highway [Jonathan Wacks, 1989], Smoke Signals [Señales de humo, Chris Eyre, 1998]), afroamericanos (Love Field [Por encima de todo, Jonathan Kaplan, 1992], Get on the Bus [La marcha del millón de hombres, Spike Lee, 1996]), enfermos y discapacitados (Homer and Eddie [Homer y Eddie, Andrei Konchalovsky, 1989], The Sunchaser [Michael Cimino, 1996]) etc..

Thelma and Louise ocupa un lugar relevante dentro de la historia del cine de Hollywood por ser el primer film que consiguió introducir a la pareja de mujeres (female buddy couple) y el discurso feminista (a partir del guión de Callie Khourie) dentro de las convenciones del género road movie, como parte de la corriente feminista que triunfa en los 90:

Besides addressing issues of interest to the women's movement, one of Hollywood's other recent nods to feminism has been to insert women into protagonist roles in traditionally male genres such as the Western (e.g., Bad Girls [1994]; The Quick and the Dead [1995]) or the detective

13. En Smokey and the Bandit II se llega a identificar a la policía con la caballería y a los camioneros con los indios, que acuden al rescate del Bandido. La animadversión entre policías y camioneros reaparece en Convoy. 
thriller (e.g., Black Widow [1987], Blue Steel [1990]; The Silence of the Lambs [1991]; Copy Cat [1995]). As a road movie, Thelma and Louise belongs to this recent trend in Hollywood filmmaking. [...]

Thelma and Louise draws upon road movie codes, parachuting women into a traditionally male genre, to mobilize the desires of its contemporary female audience (Kotsopoulos, 2003: 11).

Entre estos códigos propios de la road movie se encuentra el subgénero de las parejas en fuga, originario del noir, en el que una pareja heterosexual se ve abocada a la delincuencia por la corrupción de la sociedad (Gun Crazy [El demonio de las armas, Joseph H. Lewis, 1950] o Bonnie and Clyde) (Kotsopoulos, 2003: 24-25). Thelma y Louise emplean la violencia para reafirmarse como mujeres dentro de una sociedad patriarcal profundamente machista, circunstancia que generó un profundo debate sobre la idoneidad de este tipo de discurso feminista, calificado por diversos críticos, como Shapiro (1991), Schickel (1991) y Leo (1991), de gratuito, fascista o tóxico. Isabel Menéndez considera que la road movie de protagonismo femenino que prolifera en los 90 incorpora dos nuevos elementos al género: la condena de la violencia sexista y la del matrimonio como espacio de dominación, es decir, las mujeres de estas películas escapan tanto del entorno doméstico como de los malos tratos, aunque en los films normalmente no se lleguen a retratar episodios violentos (Menéndez, 2006: 425-426).

En cuanto a las primeras décadas de siglo XXI existen al menos tres fenómenos de interés: la consolidación del protagonismo femenino y el de las nuevas de las nuevas minorías, la incorporación de la familia y el boom de la comedia gamberra de carretera.

Los ancianos entran en la lista de marginados (los enfermos de los 90 seguían siendo jóvenes) a partir de The Straight Story (Una historia verdadera, David Lynch, 1999), protagonizando títulos como Barking Water (Sterlin Harjo, 2009) o Nebraska (Alexander Payne, 2013). Hasta ahora las personas mayores habían representado la ley y el hogar, en contraposición a los jóvenes descontentos que reaccionaban echándose a la carretera. El interés por el punto de vista de los mayores, y en general por el de todas las nuevas minorías, favorece la recuperación de la carga contracultural 
del género (Laderman, 2000: 237). Un porcentaje considerable de las road movies estrenadas en los últimos años tienen como protagonista a un representante de alguno de estos grupos, como Road to Paloma (Jason Momoa, 2014), sobre un indio mojave o The Fundamentals of Caring (Los principios del cuidado, Rob Burnett, 2016), sobre un adolescente con distrofia muscular.

La inexistencia de familias viajeras dentro de la road movie se explica porque la familia representa la estabilidad, lo colectivo (la sociedad en última instancia), los límites al desarrollo individual de unos protagonistas que sólo se realizan cuando la abandonan; aunque existen algunas excepciones, como Natinal Lampoon's Vacation (Las vacaciones de una chiflada familia americana, Harold Ramis, 1983), en la que un matrimonio y sus dos hijos se embarcan en un viaje por carretera desde Chicago hasta California para visitar el parque temático Walley World, deudora de la corriente paródica inaugurada por Smokey and the Bandit y primera entrega de otra larga saga ${ }^{14}$. En cualquier caso, la proliferación de la familia on the road no se produce hasta el siglo XXI, con un título especialmente emblemático: Little Miss Sunshine (Pequeña Miss Sunshine, Jonathan Dayton y Valerie Faris, 2006), que relata el viaje de una familia media baja desestructurada unida por la posibilidad de ganar un concurso de belleza infantil (irónica recreación del sueño americano vaciada de trascendencia). En We're the Millers (Somos los Miller, Rawson Marshall Thurber, 2013), un vulgar camello recluta a una stripper y dos adolescentes (un novato y una joven experimentada) para poder pasar de México a EE.UU. un cargamento de marihuana sin llamar la atención (como la típica familia americana). Durante el viaje los cuatro personajes se conocen y al final terminan formando una auténtica familia. Una trama que se repite con relativa frecuencia es la de padre/ madre que estrecha los lazos con su hijo durante un viaje: Around the Bend (A la vuelta de la esquina, Jordan Roberts, 2004), The Open Road (Michael Meredith, 2009) o The Guilt Trip (Un desmadre de viaje, Anne Fletcher, 2012). La pareja on the road se impone pues, frecuentemente, a la familia al completo: en Tammy (Ben

14. A saber: Natinal Lampoon's European Vacation (Las vacaciones europeas de una chiflada familia americana, Amy Heckerling, 1985), National Lampoon's Christmas Vacation (;Socorro! Ya es Navidad, Jeremiah S. Chechik, 1989), Vegas Vacation (Vacaciones en Las Vegas, Stephen Kessler, 1997) y la reciente Vacation (Vacaciones, John Francis Daley y Jonathan Goldstein, 2015), en la que el hijo de los Griswold, ya adulto, embarca a su familia en el mismo viaje de la primera entrega. 
Falcone, 2014), remedo cómico de Thelma and Louise, está formada por una joven obesa y su abuela (interpretada por Susan Sarandon).

La comedia gamberra de carretera surge del maridaje entre la comedia gamberra y la road movie. De la primera se toma el gusto por la grosería más burda (lenguaje procaz, contenido sexual y escatológico), el protagonismo coral (generalmente masculino, abundan los jóvenes universitarios) y la acumulación de episodios cómicos ${ }^{15}$. De la segunda: la presencia de un viaje por carretera cuyas diferentes paradas jalonan el relato, los encuentros con una amplia gama de personajes y la acumulación de una serie de experiencias que transforman a los protagonistas (viaje exterior $=$ viaje interior). La estructura de la road movie favorece la fragmentación narrativa, en episodios, lo cual se adapta perfectamente al desarrollo en sketches característico de la comedia gamberra. En realidad, se trata de una versión renovada de las comedias de persecuciones (saga Smokey and the Bandit), carreras (saga del Cannonball ${ }^{16}$ ) o vacaciones familiares (saga National Lampoon's Vacation) propias de los 80 , sólo que ahora se pone un mayor énfasis en lo grotesco y en el simbolismo del viaje (por eso hemos hablado de maridaje entre géneros).

El film inaugural es Road Trip (Viaje de pirados, Todd Phillips, 2000), que recrea el alocado periplo de cuatro jóvenes universitarios. Este modelo se adaptó posteriormente al protagonismo de americanos (físicamente) más maduros: Wild Hogs (Cerdos salvajes con un par... de ruedas, Walt Becker, 2007); a la incorporación de chicas: We're the Millers; minorías raciales: Harold \& Kumar Goes to White Castle (Dos colgaos muy fumaos, Danny Leiner, 2004); e incluso inmigrantes: Borat. Cultural Learnings of America for Make Benefit Glorious Nation of Kazakhstan (Borat, Larry Charles, 2006).

\section{CONCLUSIONES}

La road movie es un objeto de estudio controvertido. En las últimas décadas ha dado lugar a numerosas publicaciones que discrepan en cuanto a su origen y encuentran dificultades para definir de forma exclusiva su

15. Popularmente se considera a National Lampoon's Animal House (Desmadre a la americana, John Landis, 1978) como la inauguradora del género.

16. The Cannonball Run (Los locos del Cannonball, Hal Needham, 1981), Cannonball Run II (Los locos del Cannonball II, Hal Needham, 1984) y Speed Zone! (Los locos del Cannonball III, Jim Drake, 1988). 
carácter autónomo frente a otros géneros anteriores.

Algunos autores consideran a la road movie un fenómeno transnacional unido al desarrollo de la movilidad (Orgeron), otros creen que convivió con los géneros del cine clásico norteamericano (Cohan y Hark). Aquí hemos intentado demostrar que, a pesar de ser un género menor (un intergénero, según Sánchez Noriega), la road movie posee un origen preciso, una poética propia y una evolución que comporta la incorporación de cambios sustanciales.

La road movie nace en EE.UU. a finales de los 60 a partir de una serie de elementos preexistentes típicamente norteamericanos (el espíritu renovador de la extensión de la frontera, la highway culture y la contracultura), coincidiendo con el periodo conocido como New Hollywood (19671975).

Sus rasgos característicos son: la estructura narrativa en torno al desplazamiento por carretera; el empleo de unos recursos técnicos concretos (camera car); el sentido metafórico del viaje, entendido como iniciación o aprendizaje; y su capacidad para retratar la sociedad del momento.

Bonnie and Clyde y Easy Rider marcan las dos líneas temáticas de desarrollo de la road movie contracultural durante los primeros 70: la huida (key outlaw road movies) y la búsqueda existencial (quest road movies) respectivamente; así como el predominio de la pareja masculina o heterosexual. Con la irrupción de la posmodernidad a mediados de los 70 el género inicia una fase revisionista y autorreflexiva: sus protagonistas habitualmente pertenecen al establishment, y se critica la yuppie culture, como en Rain Man; otra vía muy transitada es la deconstrucción de la road movie en clave paródica, como en la saga de Smokey and the Bandit. En los 90, el hombre blanco joven heterosexual (american male), protagonista canónico del género, se ve desplazado por otras alternativas sexuales y raciales: mujeres, gays, indios americanos, afroamericanos, enfermos y discapacitados. La película bisagra es Thelma and Louise. En las primeras décadas de siglo XXI existen tres fenómenos de interés: la consolidación del protagonismo femenino y el de las nuevas minorías con la entrada de los ancianos (a partir de The Straight Story), la incorporación de la familia (en títulos como Little Miss Sunshine) y el boom de la comedia gamberra de carretera (a partir de Road Trip). 


\section{REFERENCIAS BIBLIOGRÁFICAS}

ARCHER, N. (2013). The French Road Movie. Space, Mobility, Identity. New York: Berghahn. (2016). The Road Movie. In Search of Meaning. New York: Wallflower Press.

ALTMAN, R. (1984). "A Semantic/Syntactic Approach to Film Genre". Cinema Journal 23 (3), 6-18.

ATKINSON, M. (1994). "Crossing the Frontiers". Sight and Sound 4 (1), 14-17.

BARRIOS, M. (2001). Narrar el abismo. Ensayos sobre Nietzsche, Hölderlin y la disolución del clasicismo. Valencia: Pre-Textos.

BISKIND, P. (2004). Moteros tranquilos, toros salvajes. La generación que cambió Hollywood. Barcelona: Anagrama.

BOURDIEU, P. (1991). El sentido práctico. Madrid: Taurus. (2000). La dominación masculina. Barcelona: Anagrama.

BRANDELLERO, S. (ed.) (2013). The Brazilian Road Movie. Journeys of (Self) Discovery. Cardiff: University of Wales.

COHAN, S. \& HARK, I. R. (1997). "Introduction". En The Road Movie Book, S. Cohan y I. R. Hark (eds.), 1-14. New York: Routledge.

COOK, B. (2011). La generación beat. Crónica del movimiento que agitó la cultura y el arte contemporáneo. Barcelona: Ariel.

COOK, D. A. (2002). Lost Illusions. American Cinema in the Shadow of Watergate and Vietnam, 1970-1979. New York: Charles Scribner's Sons.

CORRIGAN, T. (1991). "Genre, Gender and Hysteria: The Road Movie in Outer Space". En A Cinema Without Walls: Movies and Culture after Vietnam, T. Corrigan, 137-160. New Brunswick: Rutgers University. CUNNELL, H. (2007). "Fast This Time. Jack Kerouac and the Writing of On the Road". En On the Road: The Original Scroll, H. Cunnell (ed.), 1-52. New York: Viking.

DE LAURENTIS, T. (1985). "The Rhetoric of Violence". Semiotica 54 (1-2), 11-32.

ELSAESSER, T. (1975). "The Pathos of Failure: Notes on the Unmotivated Hero". Monogram 6, 13-19.

FRASCA, G. (2001). ROAD MOVIE. Immaginario, genesi, struttura e forma del cinema americano on the road. Torino: UTET. 
INDURÁIN ERASO, C. (2001). “Thelma and Louise: 'Easy Riders' in a male genre". Atlantis 23 (1), 63-73.

KLEPARSKI, G. \& MARTYNUSKA, M. (2008). "The image of POLICE OFFICER as emerging from road movies and road lingo". Studia Anglica Resoviensia 51 (5), 70-84.

KOTSOPOULOS, A. (2003). "Gendering Expectations: Genre and Allegory in Readings of Thelma and Louise". Left History 8 (2), 10-38.

LADERMAN, D. (2002). Driving Visions. Exploring the Road movie. Austin: University of Texas.

LA POLLA, F. (1978). "Poetiche dell'iperrealismo". En Il nuovo cinema americano (1967-1975), F. La Polla, 163-187. Venezia: Marsilio.

LEO, J. (1991). "On Society: Toxic Feminism on the Big Screen". US News \& World Report 10 June, 20.

LOTMAN, Y. (1979). "The Origin of Plot in the Light of Tipology". Poetics Today 1 (1-2), 161-184.

MARCHESE, A. y FORRADELLAS, J. (1998). Diccionario de retórica, crítica y terminología literaria. Barcelona: Ariel.

MAZIERSKA, E. \& RASCAROLI, L. (2006). Crossing New Europe: Postmodern Travel and The European Road Movie. London: Wallflower.

MENÉNDEZ, I. (2006). “Cuando ellas escapan: las road movies y las mujeres”. En Mujeres, espacio y poder, M. Arriaga Flórez (dir.), 418431. Madrid: Arcibel.

MULVEY, L. (1975). "Visual Pleasure and Narrative Cinema". Screen 16 (3), 6-18.

ORGERON, D. (2008). Road Movies. From Muybridge and Mèlies to Lynch and Kiarostami. New York: Palgrave Macmillan.

PÉREZ, J. (2011). Cultural Roundabouts: Spanish Film and Novel on the Road. Lewisburg: Bucknell University Press.

RASCAROLI, L. (2005). "Carlo Mazzacurati, Silvio Soldini, and Gianni Amelio: Highways, Side Roads, and Borderlines -the New Italian Road Movie". En Italian Cinema. New Directions, W. Hope (ed.), 251-271. Bern: Peter Lang AG/European Academic Publishers.

SÁNCHEZ NORIEGA, J. L. (2002). Historia del cine. Teoría y géneros cinematográficos, fotografía y televisión. Madrid: Alianza.

SCHICKEL, R. (1991). "Cover Stories: Gender Bender". Time 24, June, 52-55. 
SHAPIRO, L. (1991). “Women Who Kill Too Much”. Newsweek 17, June, 63.

TURNER, F. J.. (1961). "The Significance of the Frontier in American History (1893-4)". En Frontier and Section. Selected Essays of Frederick Jackson Turner, R. A. Billington (ed.), 37-62. Englewood Cliffs (N.J.): Prentice-Hall.

WEINRICHTER, A. (1979). El Nuevo Cine Americano. Aproximación al cine americano de los años setenta desde una perspectiva de los géneros. Bilbao: Zero.

Recibido el 24 de marzo de 2017.

Aceptado el 28 de abril de 2017. 